\title{
Ground support design for weak rock mass: quantifying time-dependent closure in squeezing ground
}

\author{
SN Warren National Institute for Occupational Safety and Health, USA \\ R Pakalnis Pakalnis \& Associates, and The University of British Columbia, Canada \\ MJ Raffaldi RESPEC Consulting, USA \\ DJ Benton National Institute for Occupational Safety and Health, USA \\ L Sandbak Barrick Gold Corporation, USA \\ CK Barnard Golder Associates Inc., USA
}

\begin{abstract}
Mining in weak and highly fractured rock can result in hazardous mining conditions and poses challenges to designing appropriate ground support for the intended use of the excavation. Production levels and infrastructure often require different support strategies because of varying tolerance to time-dependent closure and squeezing ground conditions. This paper presents an empirically derived ground support design methodology that estimates squeeze rate as a function of $W$-RMR and ground support capacity. This information aids the engineer in designing ground support appropriate to rock mass conditions and intended excavation use, thereby increasing confidence in support design and improving safety in underground mines.
\end{abstract}

Keywords: mining, ground support, weak rock mass, squeezing ground, time dependent, convergence

\section{Introduction}

Weak rock mass conditions at underground mines can pose challenges to installing an appropriate amount of ground support for the intended use and lifespan of an excavation. Production levels and infrastructure often require different support strategies because of varying tolerance to time-dependent closure and squeezing ground conditions. This paper presents empirically derived estimates of squeezing ground rates based on support capacity and geotechnical conditions from case histories in Nevada gold mines. Guidelines for ground support are provided based on the intended excavation use.

Experience has shown that estimating an appropriate amount of ground support in overstressed squeezing ground is not trivial, and few design tools have proven effective in doing so for underground gold mines in Nevada. This can result in (1) excessive excavation deformation (squeeze) that damages excavation support and reduces its capacity, and (2) hazardous groundfalls or fall of ground. Beauchamp (2006) states 'the design of ground support at a mining operation is still largely an art rather than an exact science.' The authors hope this research advances the science of ground support design and provides engineers with more confidence in their designs.

Researchers at the Spokane Mining Research Division (SMRD) of the National Institute for Occupational Safety and Health (NIOSH) are working with industry practitioners to increase the reliability of and confidence in installed ground support by developing experience-based ground support design guidelines. The authors intend these guidelines to assist in estimating the appropriate amount of ground support for an excavation based on its intended use, tolerance to squeezing ground, and rehabilitation frequency. This research is part of a lineage of previous research in weak rock mass ground support including:

- Span design for entry-type excavations (Lang 1994). 
- Empirical approaches for weak rock masses (Brady et al. 2005).

- Update of span design curve for weak rock masses (Ouchi et al. 2008).

- Empirical design methods in practice (Pakalnis 2015).

- Empirical ground support recommendations for underground gold mines in Nevada (Warren \& Kallu 2016).

- Ground support design curves: Squeezing ground in Nevada (Warren et al. 2018).

The ground support design curves presented in this paper build on the work of Ouchi et al. (2008) and Warren et al. (2018) and incorporate case-history data from both studies.

\subsection{Squeezing ground-time-dependent convergence}

Squeezing ground is ground in which excavations experience large deformations or develop high ground support loads progressively over time. Cross-drift tape extensometers can be used to monitor convergence over time. Readings can be taken periodically at various locations throughout the mine to develop a sense of deformation rate. Data presented in Figure 1 show convergence at two decline locations and two production locations in an underground gold mine in northern Nevada. The decline locations squeezed 30 to $75 \mathrm{~cm}$ over an approximate 5-year period resulting in squeeze rates of roughly $15 \mathrm{~cm} /$ year or roughly $1 \mathrm{~cm} /$ month. The production locations squeezed around $25 \mathrm{~cm}$ over three months, resulting in roughly $8 \mathrm{~cm} /$ month closure. Figure 1 also hints at the differences in allowable squeeze rates for temporary and permanent excavations, which will be discussed later in this paper.

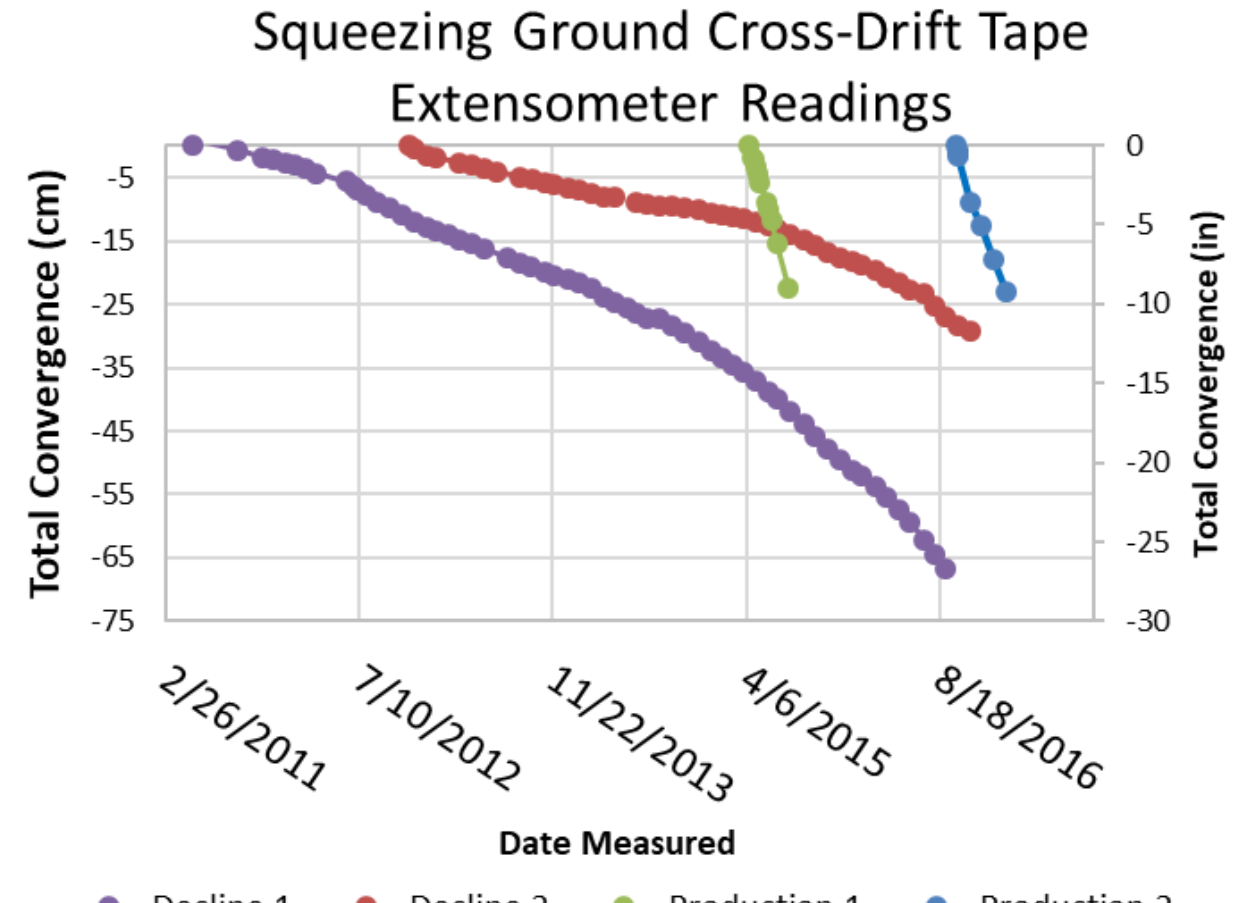

$\longrightarrow$ Decline $1 \multimap$ Decline $2 \multimap$ Production $1 \multimap$ Production 2

Figure 1 Time-dependent cross-drift tape extensometer readings from a mine in Nevada

Squeezing ground can result in broken-up shotcrete, bolt heads popping off or pulling through mesh and shotcrete (Figure 2), shoulder shear and buckling shotcrete ribs (Figure 3). As the support system is deformed and damaged, its capacity to support ground is reduced, increasing the likelihood of a groundfall. Additionally, the ground support system itself can become a groundfall hazard, particularly when shotcrete begins to break up in the back and fall, causing a striking hazard. 


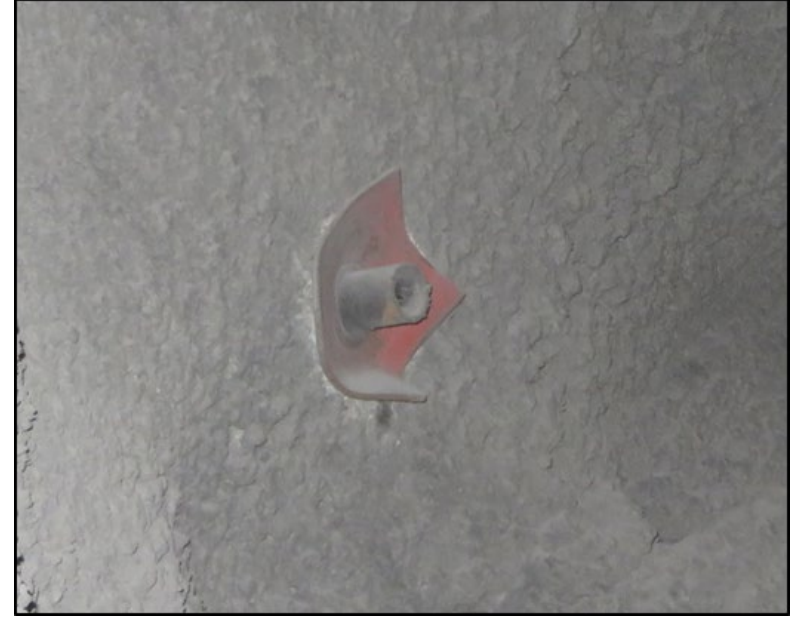

(a)

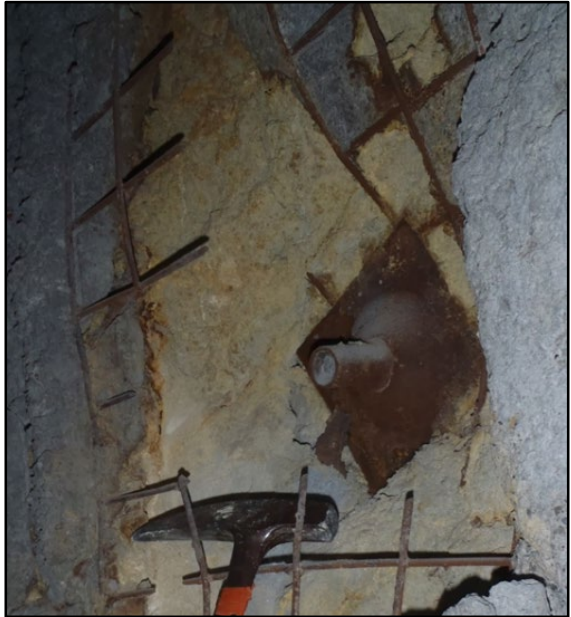

(b)

Figure 2 (a) Bolt head at beginning stages of popping off; (b) Bolt head pulled through shotcrete and welded wire mesh

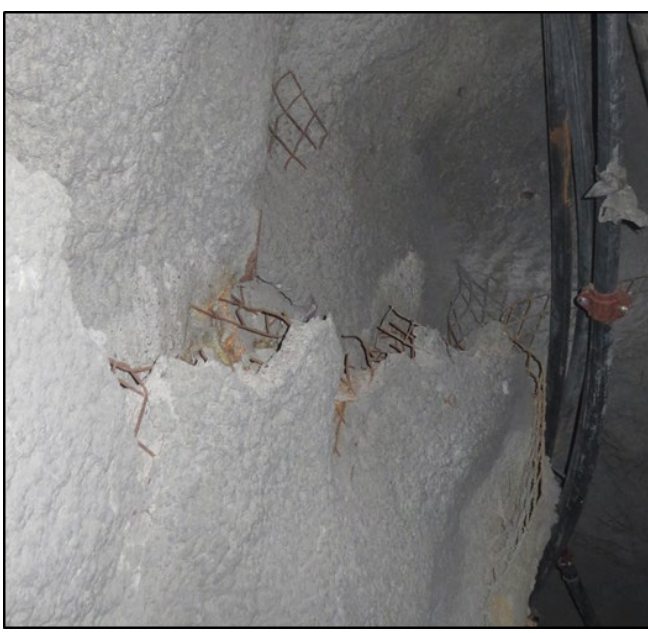

(a)

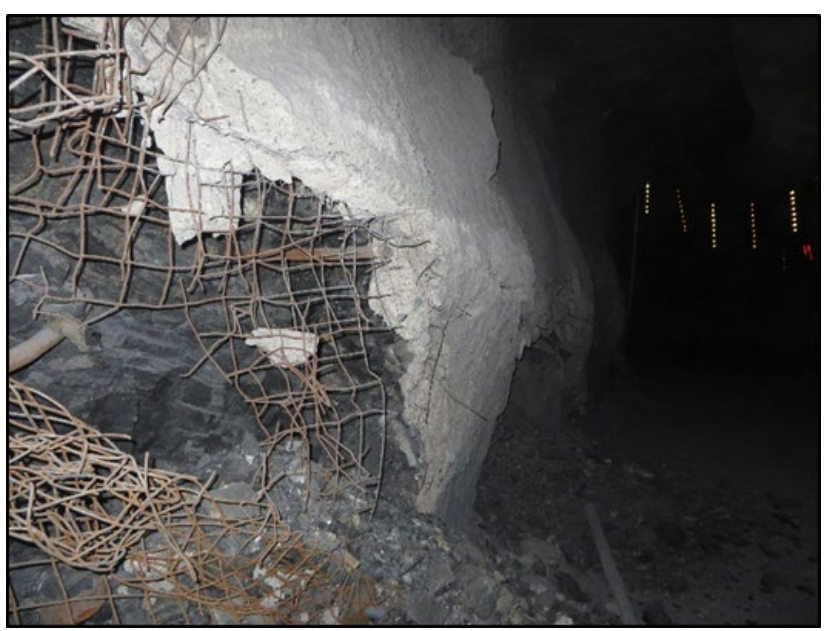

(b)

Figure 3 (a) Shoulder shear; (b) Buckled shotcrete rib

Excavation squeeze closure rates can range from essentially zero to centimetres per week, and total convergence has been measured at nearly $1 \mathrm{~m}$ in a $6 \mathrm{~m}$-wide heading ( $>15 \%$ strain). Excavations that experience squeeze are rehabilitated to the extent possible until the excavation is deemed 'lost' because it cannot be used for its intended purpose. Under these circumstances, the excavation is typically backfilled with cemented rockfill (CRF), and a decision may be made to attempt to drive an excavation next to the CRF plug.

The design capacity of a ground support system and its ability to resist or accommodate squeezing are influenced by the tolerance of an excavation to squeezing conditions and the length of time the excavation will be open. The purpose and expected lifespan of an excavation determines the tolerance to squeeze rates and total convergence. Mine-related infrastructure, such as shops, crusher chambers and backfill plants are particularly sensitive to convergence as these facilities are crucial to the operation of the mine and typically challenging to rehabilitate. In some cases, large fixed equipment is structurally attached to the ribs and/or back. Convergence that causes deformation of the fixed equipment superstructure can cause severe operational challenges and safety hazards (Figure 4). Relocation of infrastructure is costly and sometimes not possible within the financial constraints of an operation. 
Production levels, however, are typically open for a short duration and can therefore withstand higher squeeze rates and total convergence. These areas are much easier to rehabilitate because mobile equipment can be moved out of the area with the possibility of temporarily relocating mining activities while rehabilitation takes place.
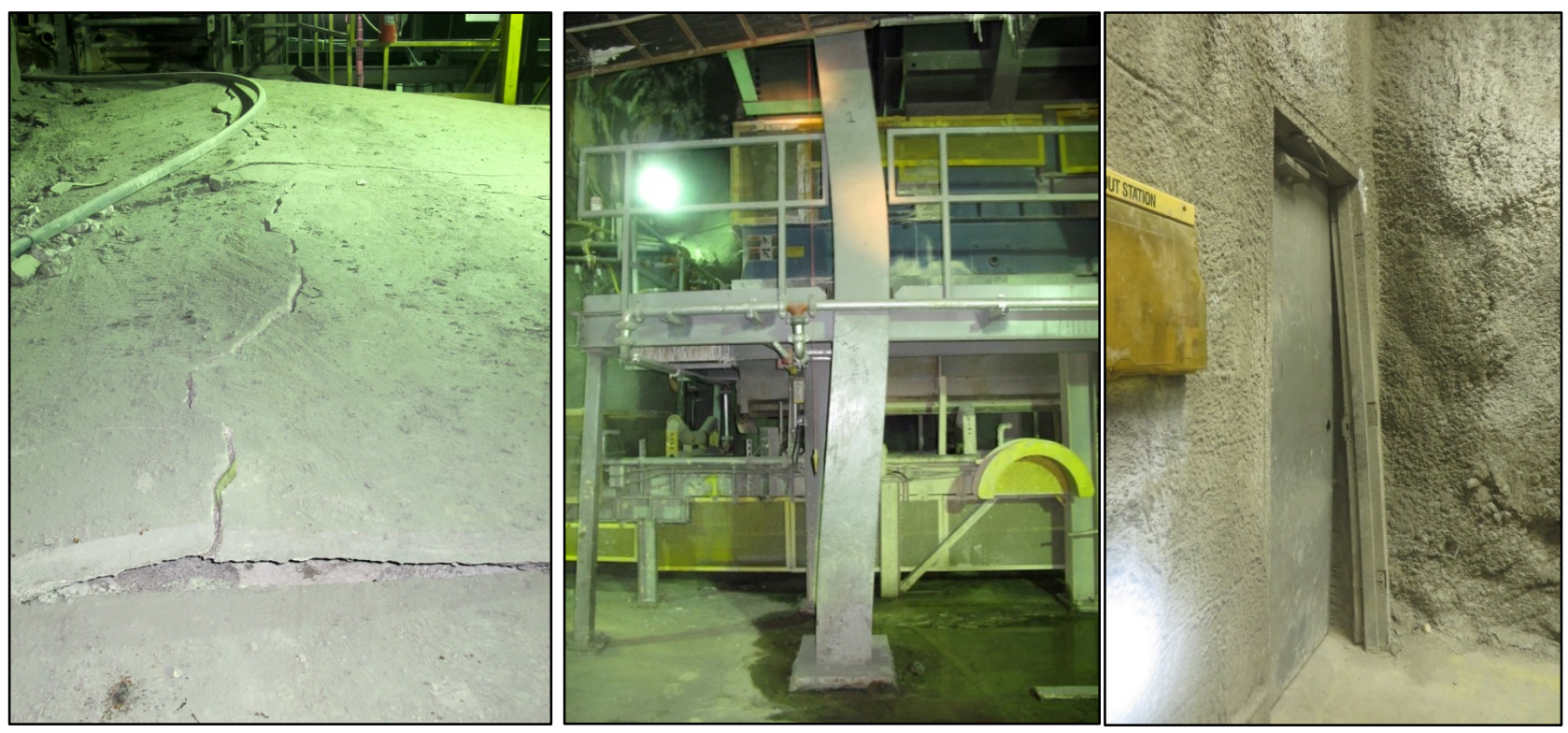

Figure 4 Infrastructure experiencing squeezing ground conditions, generally not tolerable

\section{Methodology}

The design guidelines presented in this paper were developed through the following methodology sequence:

- Development of weak rock mass ground support case-history database (data collection).

- Calculation of case-history ground support characteristics, including geotechnical conditions, ground support capacity, stress estimate, et cetera (data reduction).

- Graphical display and interpretation of ground support case history (data visualisation and analysis).

\subsection{Case-history data collection}

In an attempt to develop a current dataset for evaluation, roughly 350 ground control case histories were collected from eight operating underground gold mines in Nevada from approximately 2006 through 2014. These datasets were originally developed and augmented through a series of studies discussed in the introduction to this paper. The ground control case-history database was compiled from a combination of the authors' direct documentation of case histories and operators' geotechnical records, including operator-documented case histories, groundfall investigations, rehabilitation documentation, ground support design plans, and discussions with operators.

The majority of the case-history database was developed by the authors firsthand by visiting locations underground to document geotechnical conditions and installed ground support and by conducting stability evaluations. The documented case-history parameters are presented in Table 1. 
Table 1 Case-history data documentation parameters

\begin{tabular}{ll}
\hline Data collected & Description \\
\hline $\begin{array}{l}\text { Installed ground support } \\
\text { Geotechnical conditions }\end{array}$ & $\begin{array}{l}\text { Rockbolt type, length, spacing, capacity, surface support } \\
\text { Rock mass rating, Geological Strength Index, tunnel quality } \\
\text { index, Unified Soil Classification System }\end{array}$ \\
$\begin{array}{l}\text { Excavation parameters } \\
\text { Stability of excavation }\end{array}$ & $\begin{array}{l}\text { Dimensions, depth, age } \\
\text { Damage to rock mass and ground support 0-3 scale: } \\
\text { shotcrete cracks, bolt heads popping off, et cetera }\end{array}$ \\
\hline
\end{tabular}

\subsection{Ground support capacity}

Several methods and theories have been developed to calculate the ground support capacity, and these methods tend to differ based on the industry, the region and the common local ground control challenges. For example, 'support pressure' is the language of the tunnelling industry, and numerous design tools have been developed using this theory, which are discussed subsequently. Rockburst-prone operations are generally interested in energy absorption capacity to catch ground that has been set into motion by seismicity. Mines in Nevada have experienced numerous groundfall-related fatalities while learning to mine extremely weak rock masses and have developed kinematic methods that primarily protect mineworkers from groundfalls, but the operations do not explicitly design against squeezing ground. The following sections describe support pressure and the half-span deadweight Factor of Safety (FOS), which are the analysis methods used for the squeezing ground forecast tools presented in this paper.

\subsubsection{Support pressure}

Support pressure is defined as the equivalent normal stress applied to the excavation boundary (Hoek \& Brown 1980) presented as Equation 1.

$$
P_{S}=\frac{C_{b f 1}}{S_{r 1} * S_{l 1}}+\frac{C_{b f 2}}{S_{r 2} * S_{l 2}}
$$

where:

$$
\begin{aligned}
& P_{s}=\text { support pressure. } \\
& C_{b f 1}=\text { capacity of primary support bolt at failure or slip. } \\
& S_{r 1}=\text { primary radial bolt spacing. } \\
& S_{l 1}=\text { primary longitudinal bolt spacing. } \\
& C_{b f 2}=\text { capacity of secondary support bolt at failure or slip. } \\
& S_{r 2}=\text { secondary radial bolt spacing. } \\
& S_{l 2}=\text { secondary longitudinal bolt spacing. }
\end{aligned}
$$

Support pressure is the mobilised capacity of the support system as it takes load as represented by the ground/support reaction curve. For rockbolts, this is a function of bolt capacity and bolt spacing, represented in Equation 1. Thin-wall cylinder theory can be used to estimate support pressure from shotcrete (Hoek \& Brown 1980); however, in mining applications, shotcrete is typically considered surface support only, because drill-and-blast headings are not cylindrical, such as those excavated using a tunnel-boring machine.

Methods to estimate required support pressure have been developed by the tunnelling industry, including Barton et al. (1974), Bhasin \& Grimstad (1996) and Goel \& Jethva (1991). While civil engineering tunnels have different stability requirements from those in the mining industry, they do serve as a comparison to 
support pressure estimates developed in this paper. In particular, because of the wide acceptance of the Q-system and associated ground support design charts, the Barton et al. (1974) equation was selected as a comparison to the support pressures and squeeze rates developed for this research. As a comparative tool and for the reader's convenience, a plot of estimated required support pressure versus tunnel quality index (Q) and rock mass rating (RMR) is shown in Figure 5, using Equation 2 (Barton et al. 1974) and Equation 3 (Bieniawski 1976).

$$
\text { Support Pressure }(M P a)=\left(\frac{2.0}{J R}\right)\left(Q^{\left(-\frac{1}{3}\right)}\right)
$$

where:

$Q \quad=$ tunnel quality index.

$J R=$ joint roughness number.

$$
R M R=9 L N(Q)+4
$$

where:

$$
\begin{aligned}
& R M R=\text { rock mass rating. } \\
& Q \quad=\text { tunnel quality index. }
\end{aligned}
$$

Support Pressure vs. RMR 76 and Joint Roughness (JR)

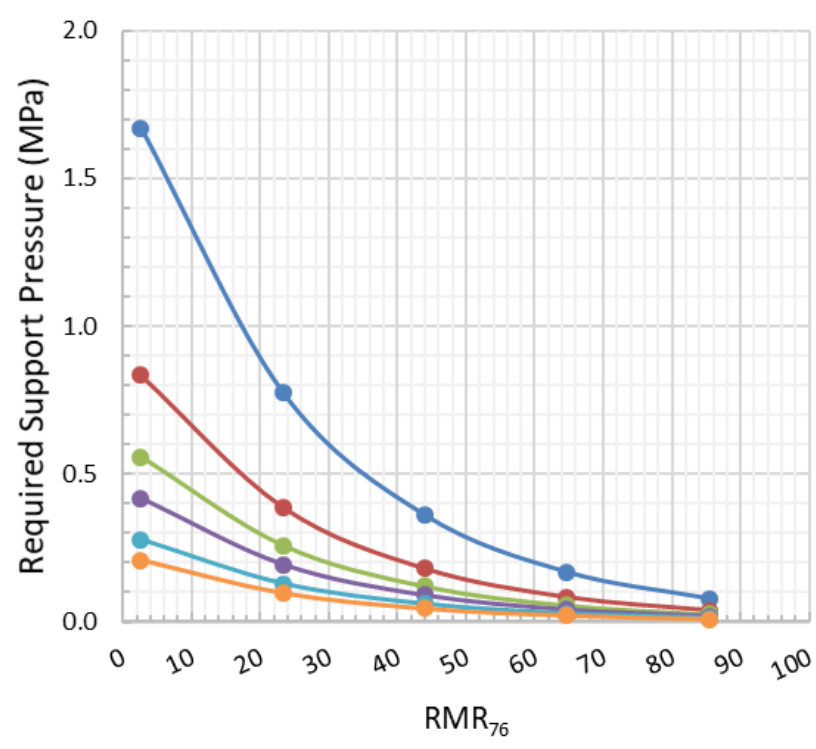

$$
\begin{aligned}
& P_{\text {roof }}=\left(\frac{2.0}{J_{r}}\right) Q^{-1 / 3} \\
& R M R=9 \ln Q+44 .
\end{aligned}
$$$$
\text { Joint Roughness (JR) }
$$

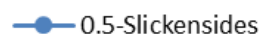

-1-Smooth and Planer

-1.5-Rough and Planer

-2 -Smooth undulating

-3-Rough and Undulating

— 4-Discontinuous Joints

Figure 5 Estimated required support pressure according to Equations 2 and 3

Figure 5 shows the non-linear nature of the relationship between required support pressure and ground conditions. The required support pressure increases more dramatically as the rock mass quality is reduced. Examples of support pressure for typical ground support are available in Hoek (1998), and support pressures are presented in Figure 6 for several common rockbolts used in mining. 


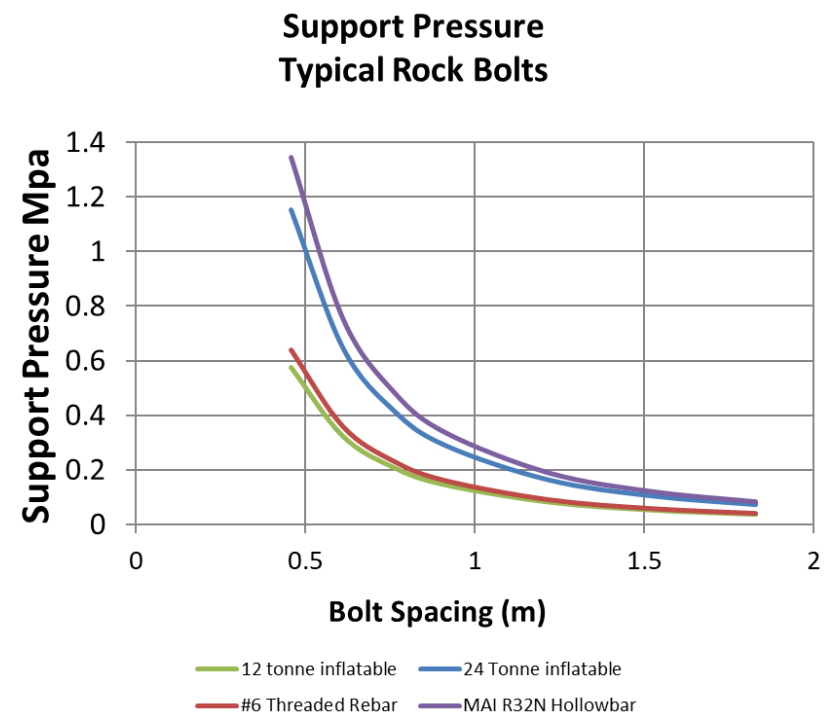

Figure 6 Support pressure provided by typical rockbolts used in mining

\subsubsection{Half-span wedge deadweight Factor of Safety}

Mine operations are typically more concerned with the clear danger of groundfalls, rather than slow, time-dependent ground movements. Therefore, kinematic deadweight FOS calculations are routinely performed by ground control engineers at underground mines. The half-span deadweight FOS (Pakalnis 2008) was developed for weak rock mass conditions or for when detailed discontinuity orientation data are not available for 3D kinematic analysis. The design method has gained wide acceptance at mine operations in Nevada and worldwide (Pakalnis 2015), and this paper takes the familiar FOS deadweight design concept and applies it to squeezing ground conditions.

The half-span deadweight FOS design method presented in Pakalnis (2008) assumes a failure surface that is approximated as a wedge whose height is equal to one-half the excavation span, with support capacity defined by the breaking and bond strength of a rockbolt. The FOS calculation is presented in Equation 4.

$$
F O S=\frac{S_{c}}{W_{w}}
$$

where:

$$
\begin{aligned}
F O S= & \text { kinematic Factor of Safety against deadweight wedge groundfall. } \\
S_{C}= & \text { deadweight capacity of the support system passing above the assumed wedge failure } \\
& \text { plane. } \\
W W= & \text { weight of the wedge. }
\end{aligned}
$$

Factors contributing to FOS calculation are presented in Table 2.

The calculation is essentially a kinematic wedge analysis (Figure 7) with support capacity defined as the value of the sum of the individual bolt capacities, which is the lesser of the breaking strength or the bond strength of the bolts passing through the failure surface (Pakalnis 2008). The wedge weight is determined by calculating the volume of the wedge, assuming an in-plane thickness equal to the in-plane bolt spacing, and multiplying by the unit weight. 
Table 2 Factors affecting Factor of Safety calculation

\begin{tabular}{ll}
\hline Parameter & Comment \\
\hline Bolt capacity & Manufacturer defined \\
Bolt bond strength & Estimated or measured with bolt pull tests \\
In-plane bolt spacing & User defined \\
Out-of-plane bolt spacing & User defined \\
Excavation span & Operational requirement \\
Ground unit weight & Measured or assumed \\
\hline
\end{tabular}

"DEAD WEIGHT" ANALYSIS: WEDGE HEIGHT $=0.5 \times$ SPAN

SUPPORT PATTERN: 2.4m LONG \#6 REBAR ON 1m X 1m PATTERN BOND PAST WEDGE

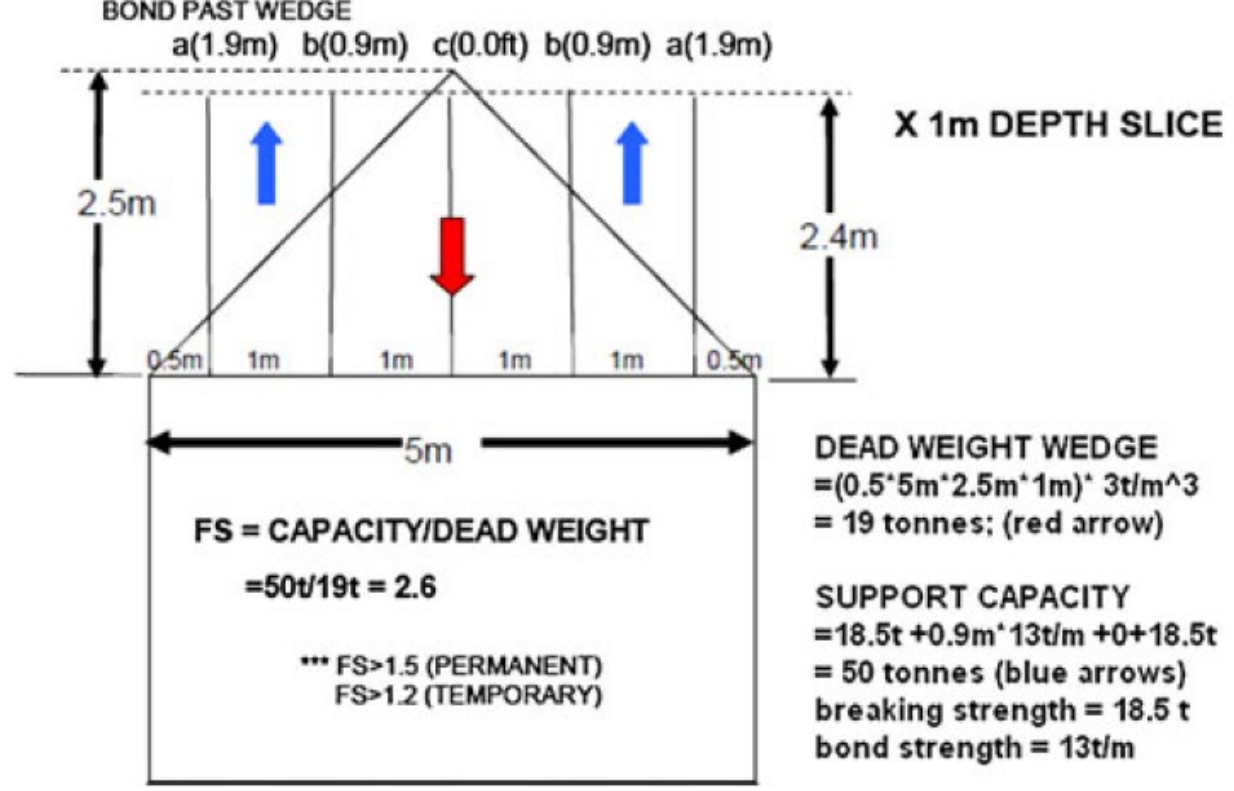

Figure 7 Deadweight Factor of Safety calculation from Pakalnis (2008)

Because of its widespread use, NIOSH SMRD, in conjunction with Pakalnis and Associates, has developed a digital-platform-hosted half-span FOS calculator, available in beta release. The half-span deadweight FOS method is easily understood and effective, and it has a robust history for designing against groundfalls.

\subsubsection{Correlation of support pressure and half-span wedge deadweight Factor of Safety}

Support pressure and half-span deadweight FOS are two common methods used to quantify ground support in the mining industry, making a comparison of the methods useful. It also makes guidelines presented in this paper relatable to a wider audience. Table 3 highlights the major differences between the two ground support capacity calculations. Both calculation methods are useful and have merit. The most significant difference between the methods is that support pressure is not affected by bolt length or excavation dimension. This is an interesting point to make given that the $Q$ equation developed by Barton el al. (1974) intentionally ignores excavation dimensions, and their paper clearly states that there is no relation between required support pressure and excavation diameter. However, it does indicate that bolt length should increase as dimension increases. Many methods developed by Pakalnis et al. have incorporated span into the design process, including the half-span FOS. The debate on the influence of excavation size on ground support design will not be settled here, though a correlation between support pressure and half-span FOS developed from the case-history database is presented on Figure 8. 
Table 3 Differences between support pressure and half-span deadweight Factor of Safety

\begin{tabular}{|c|c|c|}
\hline Parameter & Support pressure & Half-span deadweight Factor of Safety \\
\hline Bolt capacity & Considered & Considered \\
\hline Bolt bond strength & $\begin{array}{l}\text { Determined by } \\
\text { pull testing }\end{array}$ & $\begin{array}{l}\text { Determined by pull testing; considered in kinematic } \\
\text { analysis }\end{array}$ \\
\hline Bolt spacing & Considered & Considered \\
\hline $\begin{array}{l}\text { Excavation } \\
\text { dimension }\end{array}$ & Not considered & $\begin{array}{l}\text { Considered directly in the calculation; significantly } \\
\text { impacts bond length }\end{array}$ \\
\hline Bolt length & $\begin{array}{l}\text { Not considered; } \\
\text { determined using } \\
\text { other methods }\end{array}$ & $\begin{array}{l}\text { Directly impacts bonded length of bolt above } \\
\text { assumed failure plane }\end{array}$ \\
\hline Ground unit weight & Not considered & $\begin{array}{l}\text { Directly impacts wedge weight and Factor of Safety } \\
\text { calculation }\end{array}$ \\
\hline
\end{tabular}

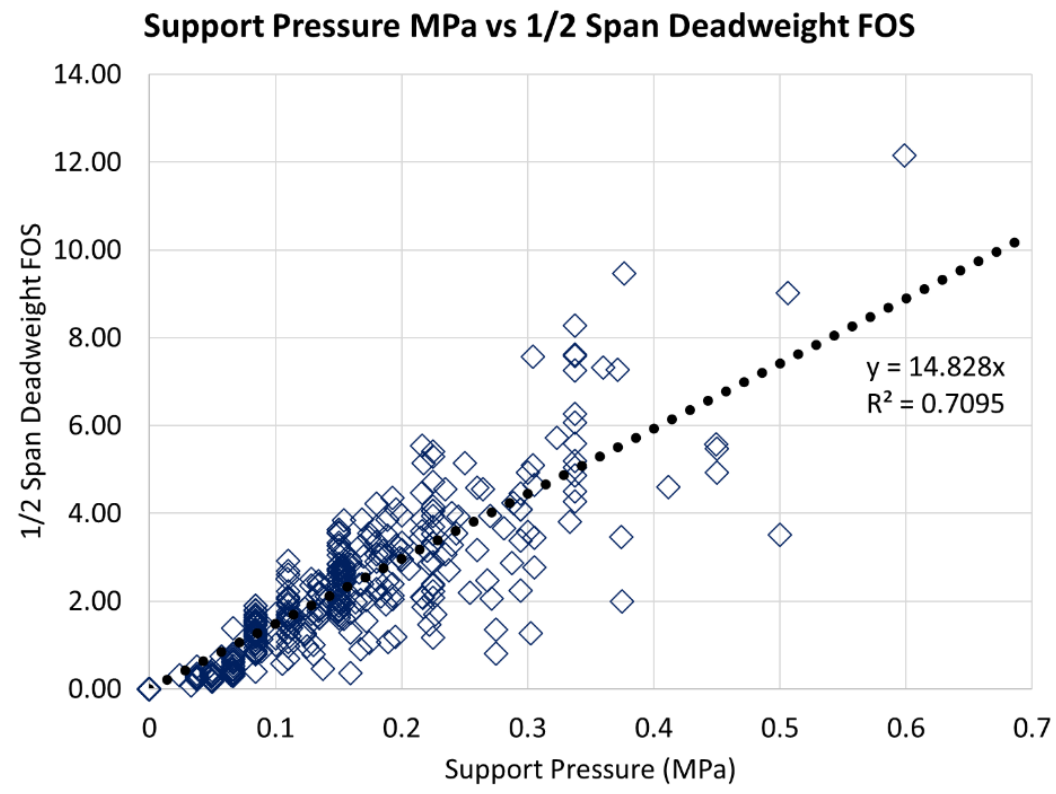

Figure 8 Support pressure (MPa) versus half-span deadweight Factor of Safety

The correlation is reasonable, and it is worth noting that many of the relatively low FOS (below the correlation line) are case studies in which both primary and secondary support are used. Since primary support is typically shorter than the secondary support, it does not extend as far beyond the assumed failure plane and is not able to mobilise its full capacity in the calculation. Recall that bolt length does not affect the support pressure calculation.

\subsection{Geotechnical calculation-weak rock mass rating}

Very poor geotechnical conditions in Nevada $(\mathrm{RMR}<25)$ represent the transition between rock and soil, and the RMR system is known to be difficult to apply and unreliable in this range (Hoek et al. 1995; Hoek \& Marinos 2007; Mathis \& Page 1995). To address issues with RMR in the lower range, the weak rock mass rating (W-RMR) was developed by incorporating engineering soil classification and calculation formulas that are roughly equivalent to traditional RMR calculation methods in moderate- to good-quality rock but increase the sensitivity of RMR in the lower range (0-25). Details of this system are available in Warren et al. (2016). W-RMR is the classification procedure used in the development of support guidelines in this paper. Below $R M R=30$, the $W-R M R$ calculation procedure is recommended because it increases RMR 
sensitivity in weak ground and allows $R M R$ to be zero. Above $R M R \sim 30, R M R$ and $W-R M R$ are essentially equal.

\subsection{Squeezing ground convergence rate estimate}

Convergence rate is defined as the amount of closure of an excavation over a given time, represented in Equation 5.

$$
\text { Convergence } \text { Rate }=\frac{\text { Estimated Excavation Convergence }}{\text { Time }}
$$

The amount of time taken to squeeze $25 \mathrm{~mm}$ is the unit of squeeze comparison used in this paper. Ground support damage and age of excavation were documented during data collection of the case-history dataset.

In an effort to quantify the effect of ground support installation sequence, SMRD conducted deformation testing of shotcrete panels. Bolt spacing and shotcrete panel thickness were kept constant at $1.2 \mathrm{~m}$ and $100 \mathrm{~mm}$, respectively. The welded wire mesh location and fibre dosage were varied. A domed $0.9 \mathrm{~m}$ diameter ram was hydraulically pushed up through the panel while monitoring ram force and displacement to quantify maximum panel bag strength and energy absorption capacity with regard to installation sequence. Details of the results can be found in Raffaldi et al. (2018).

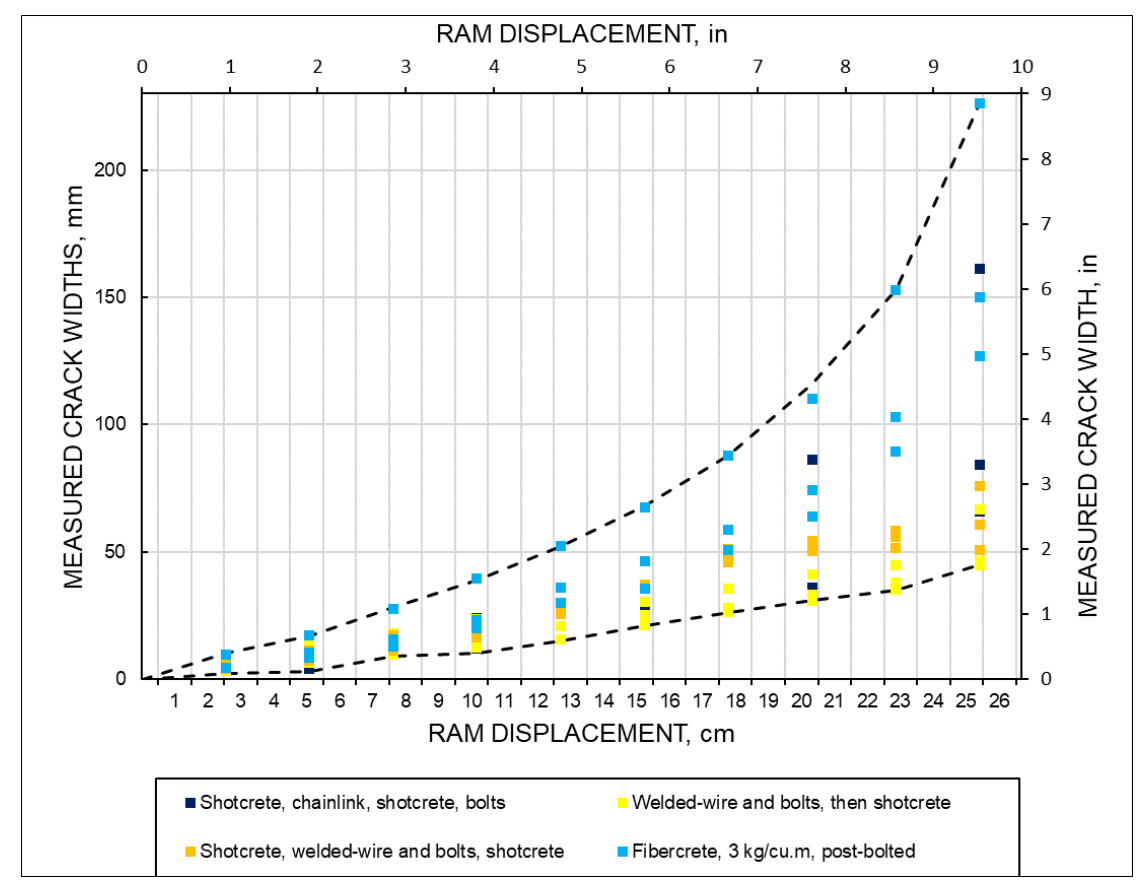

Figure 9 Ram displacement versus measured shotcrete panel crack width

A benefit of this testing was that shotcrete crack width versus ram displacement could be quantified as shown in Figure 9. By comparing the ground support damage in the case-history dataset with the crack widths shown in Figure 9, a crude estimate of excavation convergence can be made. For example, if the case history was documented to have shotcrete cracks up to $2 \mathrm{~cm}$, an assumed closure of roughly $15 \mathrm{~cm}$ was made. Note that photos were taken of most of the case histories, which were reviewed in cases where the description was not adequate to make a judgement. Also, the lead author's level of experience with collection and analysis of cross-drift tape extensometer and multi-point borehole extensometer (MPBX) data plays a role in the estimate of closure. By applying Equation 5 to the dataset, a rough estimate of convergence rate was made for the entire dataset. Total estimated convergence ranged from zero to $60 \mathrm{~cm}$, and excavation age ranged from roughly a week in production headings to 20+ years in permanent mine openings. 


\section{Data visualisation and analysis}

Figure 1 indicated that production areas may typically be allowed to squeeze at higher rates compared with development ramps and drifts. Performing separate data analysis on case histories that were separated between temporary and permanent openings does result in significant differences in forecasted squeeze rates. The authors believe that this separation is serving as a proxy for the magnitude of mining-induced stress that the excavation experiences. Standard mine design in Nevada tends to position permanent openings and infrastructure away from mine workings in an attempt to minimise mining-induced stress. Secondary development and production headings are almost certain to experience mining-induced stress, thereby experiencing higher squeeze rates for a given support pressure and W-RMR condition. The following squeeze rate analysis is conducted on (1) permanent mine excavations, including infrastructure, primary development, and exploration and (2) temporary mine openings, including secondary development, stope access and production openings.

\subsection{Permanent mine excavation (low mine-induced stress)}

Figure 10 compares squeeze rate (symbol) with W-RMR (X-axis) and support pressure ( $\mathrm{Y}$-axis) in permanent mine openings. Squeeze rate is depicted as stable (no sign of squeeze), $25 \mathrm{~mm} /$ year, $25 \mathrm{~mm} / \mathrm{month}$, and $25 \mathrm{~mm} /$ week. A clear trend is visible, with higher squeeze rates (red and yellow) occurring at low support pressures and low W-RMR conditions. Conversely, low squeeze rates and stable conditions occur at higher support pressures and higher W-RMR ratings.

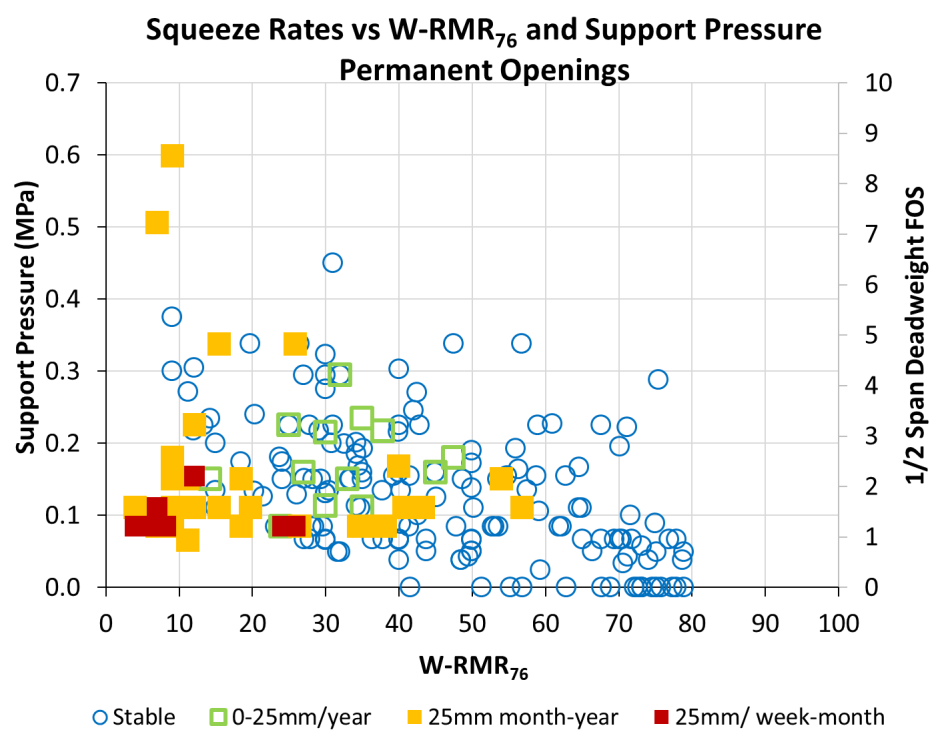

Figure 10 Permanent excavation squeeze rates versus support pressure and W-RMR

The permanent opening dataset was imported into MatLab with squeeze rate depicted on the Z (vertical) axis. A 3D surface was fitted to the data (Figure 11) using locally weighted scatter plot smoothing (LOWESS) regression. The LOWESS regression does not require specification or determination of a global function of any form to fit a model to the data. Instead, a window of influence is specified, and the method fits a surface to defined segments of the data so that multiple points influence the various portions of the model.

Figure 12 is the result of fitting a LOWESS regression model to the permanent opening case-history dataset. Squeeze rate clearly increases with reduced support pressure and in lower W-RMR rock conditions. The data were contoured to $25 \mathrm{~mm} /$ year contours such that the ' 1 ' contour represents $25 \mathrm{~mm} / \mathrm{year}$, and the ' 12 ' contour represents $12 \times 25 \mathrm{~mm} /$ year or $25 \mathrm{~mm} / \mathrm{month}$. The estimated support pressure from Barton et al. (1974; Equation 2) is plotted for reference and inferred to be the zero squeeze line, as this equation was developed essentially from tunnelling experience. The joint roughness (JR) variable in Equation 2 is 
assumed to be high, representative of good-quality rock (JR $=4$ when $R M R>80)$, and reduces as rock quality decreases $(J R=0.5$ when $R M R<20)$.

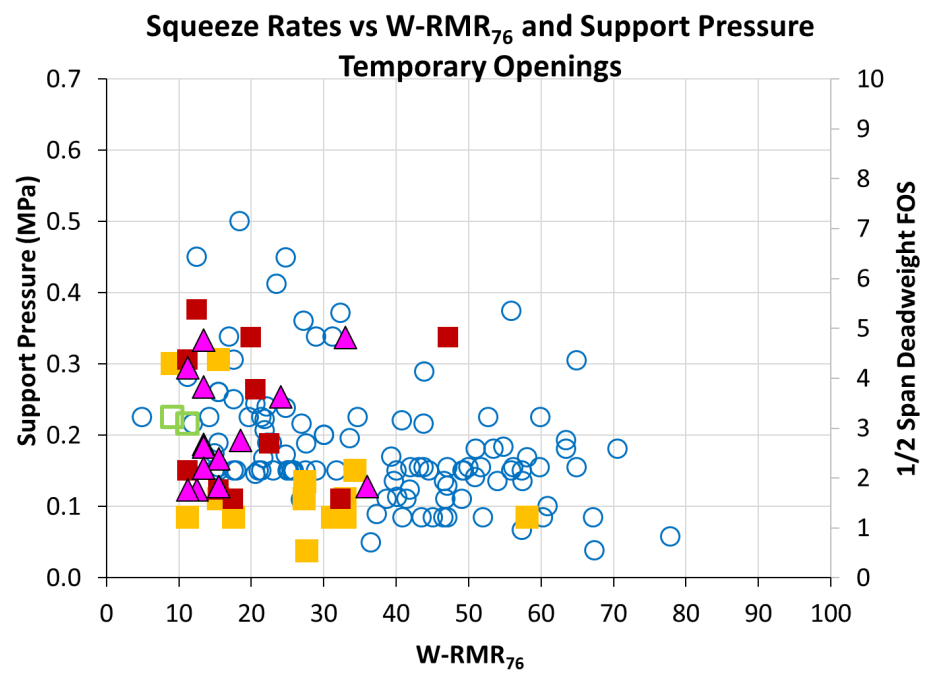

OStable $\square 0-25 \mathrm{~mm} /$ year $\square 25 \mathrm{~mm}$ month-year $\square 25 \mathrm{~mm} /$ week-month $\Delta>25 \mathrm{~mm} /$ week

Figure 11 Production and secondary development squeeze rates versus W-RMR

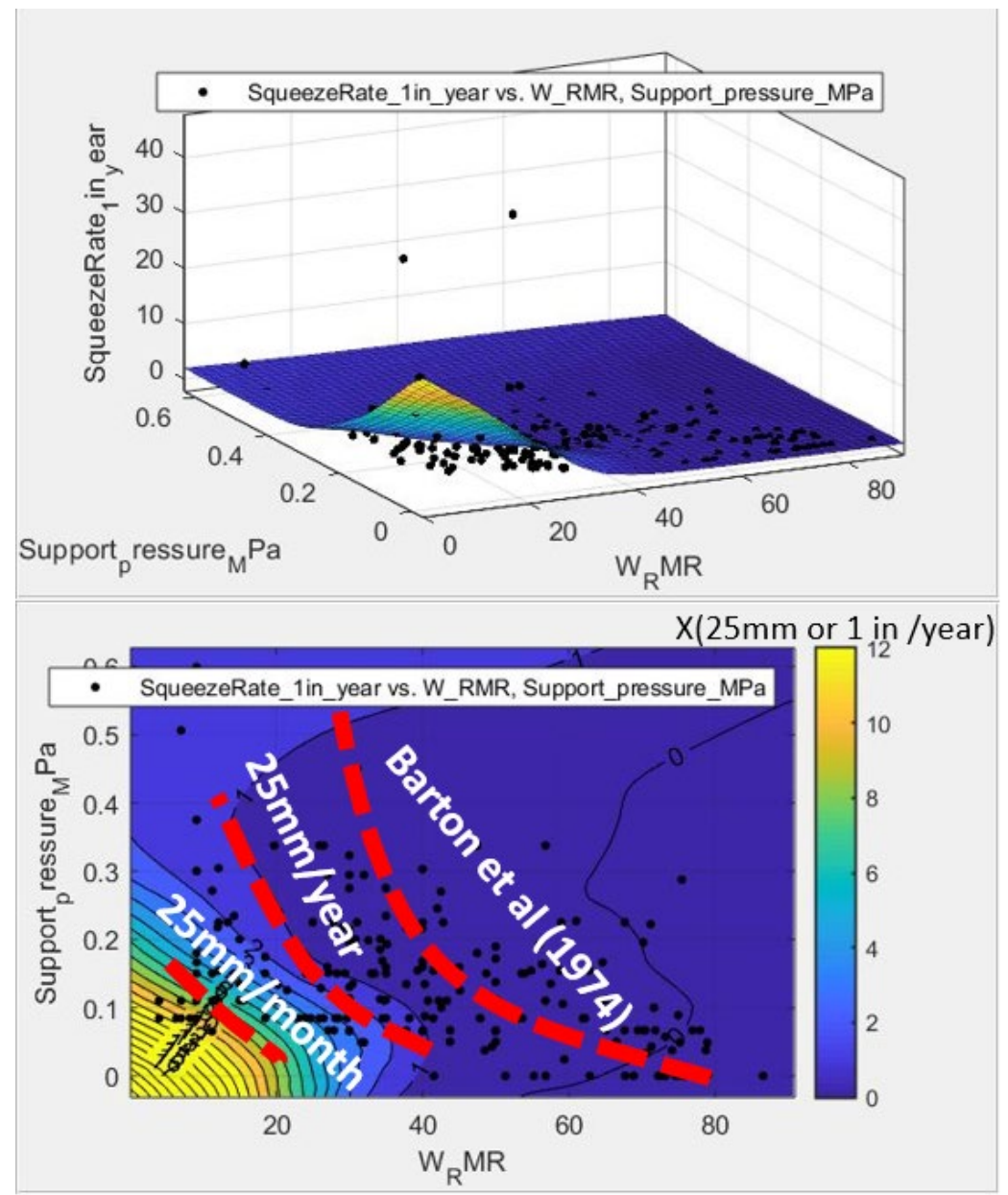

Figure 12 Permanent excavation squeeze rate contouring in MatLab using LOWESS regression

The dashed red $25 \mathrm{~mm} /$ year and $25 \mathrm{~mm} /$ month lines in Figure 12 are inferred by the authors based on (1) the LOWESS regression, (2) a current understanding of required ground support and (3) engineering 
judgement. The authors believe that this is a reasonable first-order estimate of squeeze rates to be expected in low mining-induced stress excavations in Nevada.

\subsection{Temporary mine excavations (higher mine-induced stress)}

The same analysis methodology used for the permanent excavation case histories was applied to the temporary excavation dataset, as shown in Figures 11 and 13. Squeeze rates for temporary openings are noticeably higher, exceeding $25 \mathrm{~mm} /$ week. Many of the highest squeeze rates are in stope access and tertiary developments where the active mining front was nearby or where stope barrier pillar thickness was less than designed. Some of these openings stayed open long enough to be mined and backfilled, while others had to be rehabilitated or abandoned and backfilled if rehabilitation was not possible.
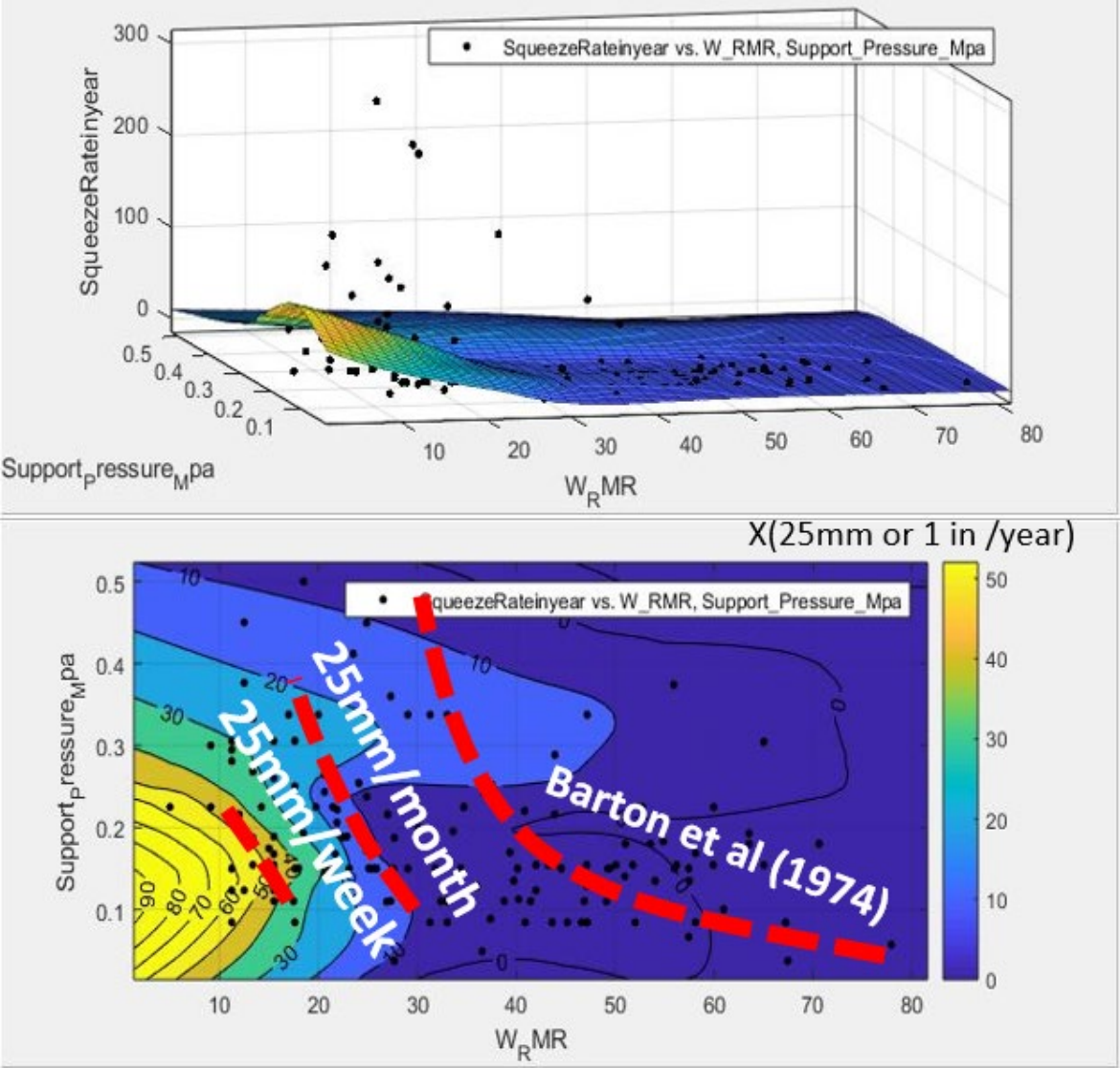

Figure 13 Temporary excavation squeeze rate contouring in MatLab using LOWESS regression

Although squeeze rates tend to be higher in temporary openings within or near the active mining zone, this is offset by the fact that they are not required to be open as long as permanent mine development. Thus, if the length of time an excavation needs to be operational and the deformation capacity of the support system is known, then the appropriate design support pressure or half-span FOS can be determined.

\section{$4 \quad$ Ground support strategy}

Choosing a support strategy will depend on the intended excavation use. Squeezing is generally tolerable in temporary mine openings as long as the support system remains intact and hazards are not created within the intended excavation lifespan. If the goal is to maximise the life of an opening, higher strain capacity ground support, such as inflatable (Swellex ${ }^{\circledR}$ type) rockbolts or yielding hollow-core groutable bolts, such as the Jenmar MPA bolt ${ }^{\circledR}$ (Faulkner et al. 2017), may be appropriate. These bolts can withstand relatively high strain (10\%) before breaking. Ideally, mining and backfilling would occur before squeezing becomes a serious problem. 
However, if the opening is for long-term or critical infrastructure, squeezing must be stopped or drastically reduced. Stiffer high-capacity bolts, such as Minova $\mathrm{MAI}^{\circledR}$, DSI $\mathrm{CT}^{\circledR}$ and rebar bolts may provide the appropriate stiffness to resist squeezing. However, these bolts can withstand strain of only a few percent before breaking and may provide less warning compared with softer support systems. A more comprehensive discussion of weak rock mass ground support strategies used in Nevada is available in Warren et al. (2018).

The authors would like to acknowledge previous research conducted on squeezing ground, and the interested reader is referred to other publications, including Hoek (1998), Potvin \& Hadjigeorgiou (2008), Hadjigeorgiou \& Karampinos (2017) and Varden \& Woods (2015).

\section{Conclusion}

Excavation squeeze rate estimates presented in this paper were developed from a case-history dataset of roughly 300 case studies documenting ground support, geotechnical conditions and an estimate of convergence rate presented in Figures 11 and 13. These Figures can serve as a first-order estimate of anticipated squeeze rates and represent a starting point for ground support design based on excavation sensitivity to squeeze and squeeze rates. If the length of time an excavation needs to be operational and deformation capacity of the support system is known, then the appropriate design support pressure or half-span FOS can be determined.

Figures 11 and 13 are not precision tools, and examination of Figures 10 and 12 shows considerable variation in squeeze rates. The authors' observations are that relatively rapid squeeze rates are typically a result of mining-induced stress, caused by either the mining front or high excavation ratios on development levels.

\subsection{Future work}

Forecasted squeeze rates presented in this paper show a correlation between estimated squeeze rates, geotechnical conditions and support capacity. The methodology described in this paper is well suited for application to more-accurate estimates of closure rate, such as cross-drift tape extensometer readings similar to those taken for Figure 1 and installed MPBX arrays. The authors would also like to expand the squeezing ground database to outside Nevada and, potentially, beyond the USA.

\section{Disclaimer}

Ground support guidelines presented in this report are based on a Unified Soil Classification System USCS/W-RMR 76 correlation, using $\mathrm{W}-\mathrm{RMR}_{76}$ equations discussed in Section 2.4. Use of traditional $\mathrm{RMR}_{76}$ classifications procedures as presented in Bieniawski (1976) will result in higher RMR values for $R M R<30$ and could result in inadequately supported ground, particularly in weak ground.

The findings and conclusions in this paper are those of the authors and do not necessarily represent the official position of NIOSH, Centers for Disease Control and Prevention (CDC). Mention of any company or product does not constitute endorsement by $\mathrm{NIOSH}$.

\section{Acknowledgement}

This paper is dedicated to the memory of Dr Rimas Pakalnis in honour of his energetic development of empirical design methods, his valuable contributions to the safety of underground mining operations throughout the world and his successful mentoring of numerous graduate students at the University of British Columbia. The authors also gratefully acknowledge the cooperation of the many Nevada operations that committed time and resources to the development of the dataset used for this research. 


\section{References}

Barton, N, Lien, R \& Lunde, J 1974, 'Engineering classification of rock masses for the design of rock support', Rock Mechanics and Rock Engineering, vol. 6, pp. 189-236.

Beauchamp, L 2006, Ground Support Manual, Mines and Aggregates Safety and Health Association, North Bay.

Bhasin, R \& Grimstad, E 1996, 'The use of stress-strength relationships in the assessment of tunnel stability', Tunnelling and Underground Space Technology, vol. 11, no. 1, pp. 93-98.

Bieniawski, Z 1976, 'Rock mass classifications in rock engineering', Proceedings of the Symposium on Exploration for Rock Engineering, vol. 1, A.A. Balkema, Rotterdam, pp. 97-106.

Brady, T, Martin, L \& Pakalnis, R 2005, 'Empirical approaches for open design in weak rock masses', Transactions of the Institution of Mining and Metallurgy, vol. 114, pp. A13-A20.

Faulkner, DD, Stankus, JC, Ma, KJ \& Ma, L 2017, August 28, 'Multiple point anchor (MPA), self-drilling, hollow core yielding bolt with injectable J-Lok $\mathrm{P}$ resin system for high-stress and squeezing ground conditions', Proceedings of the 51st U.S. Rock Mechanics/Geomechanics Symposium, American Rock Mechanics Association, Alexandria, paper ARMA 17-533.

Goel, RK \& Jethva, JL 1991, 'Prediction of support pressure using RMR classification, geotechnical analysis and performances', Proceedings of the Indian Geotechnical Conference, pp. 203-205.

Hadjigeorgiou, J \& Karampinos, E 2017, 'Design tools for squeezing ground conditions in hard rock mines', in J Wesseloo (ed.), Proceedings of the Eighth International Conference on Deep and High Stress Mining, Australian Centre for Geomechanics, Perth, pp. 693-705.

Hoek, E 1998, 'Tunnel support in weak rock', keynote address presented at the Symposium of Sedimentary Rock Engineering, Taipei, 20-22 November.

Hoek, E \& Brown, ET 1980, Underground Excavations in Rock, Institution of Mining and Metallurgy, London.

Hoek, E, Kaiser, P \& Bawden, W 1995, 'Rock mass classification', in E Hoek, PK Kaiser \& WF Bawden (eds), Support of Underground Excavations in Hard Rock, A. A. Balkema, Rotterdam, pp. 91-105.

Hoek, E \& Marinos, P 2007, 'A brief history of the development of the Hoek-Brown failure criterion', Soils and Rocks, vol. 2, November.

Lang, B 1994, Span Design for Entry-Type Excavations, master's thesis, University of British Columbia, Vancouver.

Mathis J \& Page, C 1995, 'Drifting in very poor rock-experience and analysis', paper presented at the 101st Annual Northwest Mining Association Convention, Spokane, 6-8 December.

Ouchi, AM, Pakalnis, R \& Brady, TM 2008, 'Empirical design of span opening in weak rock based upon support type employed', Proceedings of the 99th Annual American Rock Mechanics Association, American Rock Mechanics Association, Alexandria.

Pakalnis, R 2008, 'Methodology towards ground support', in J Hadjigeorgiou (ed.), Proceedings of Third International Symposium on Strategic vs Tactical Approaches in Mining, Laval University, Quebec City.

Pakalnis, R 2015, 'Empirical design methods in practice', in Y Potvin (ed.), Proceedings of the International Seminar on Design Methods in Underground Mining, Australian Centre for Geomechanics, Perth, pp. 37-56.

Potvin, Y \& Hadjigeorgiou, J 2008, 'Ground support strategies to control large deformations in mining excavations', Journal of the Southern African Institute of Mining and Metallurgy, vol. 108, no. 7, pp. 397-404, http://www.scielo.org.za/ scielo.php?script=sci_arttext\&pid=S2225-62532008001200004\&Ing=en\&tIng=en.

Raffaldi, MJ, Warren, SN, Martin, LA, Stepan, MA, Pakalnis, R \& Sandbak, LA 2018, August 21, 'Reinforced shotcrete performance: quantifying the influence of ground support installation sequence', Proceedings of the 52nd U.S. Rock Mechanics/Geomechanics Symposium, American Rock Mechanics Association, Alexandria, ARMA 18-566.

Varden, RP \& Woods, MJ 2015, 'Design approach for squeezing ground', in Y Potvin (ed.), Proceedings of the International Seminar on Design Methods in Underground Mining, Australian Centre for Geomechanics, Perth, pp. 489-504.

Warren, SN \& Kallu, RR 2016, 'Empirical ground support recommendations for underground gold mines in Nevada', Proceedings of the 50th U.S. Rock Mechanics/Geomechanics Symposium, American Rock Mechanics Association, Alexandria, paper ARMA $16-688$.

Warren, SN, Kallu, RR \& Barnard, CK 2016, 'Correlation of the rock mass rating (RMR) system with the unified soil classification (USCS): introduction of the weak rock mass rating system (W-RMR)', Rock Mechanics and Rock Engineering, vol. 49, pp. 4507-4518.

Warren, SN, Raffaldi, MJ, Martin, LA, Pakalnis, R \& Barnard, CK 2018, 'Ground support design curves: squeezing ground in Nevada', Proceedings of the 50th U.S. Rock Mechanics/Geomechanics Symposium, American Rock Mechanics Association, Alexandria, paper ARMA 18-750. 
Ground support design for weak rock mass:

SN Warren et al.

quantifying time-dependent closure in squeezing ground 